\title{
PRECAD $^{\circledast}$, A COMPUTER ASSISTED DESIGN AND MODELLING TOOL FOR
}

\section{SUPERALLOY POWDER PRECISION MOULDING}

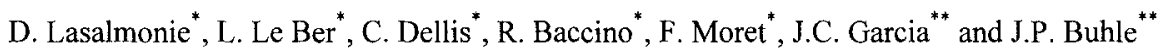 \\ ${ }^{*}$ CEA/CEREM - 17, rue des Martyrs, 38054 Grenoble Ccdex 9, France \\ ** TURBOMECA, 40220 Tarnos, France
}

\begin{abstract}
$\underline{\text { Abstract }}$
This paper presents a computer assisted design and modelling tool, PRECAD®, developed by CEA/CERUM and its appplication to superalloy powder precision moulding. This tool includes a computer assisted design (CAD) module that enables the design of part, container and cores used to produce net-shape product from superalloy powder. The meshes of the different components are automatically generated in this module, even for complex 3Dgeometry. A coupled FEM module modelled the HIP process using meshes and limit conditions generated by the CAD module. Powder data base is now available for titanium base alloys, stainless steel and nickel base superalloy SY625 produced by TECPHY. Data base for steel container and cores is also available for a large range of temperature. Deformed mesh is visualized on the CAD module and compared with initial and desired final shapes. Container and cores geometry can be optimized in order to produced the net-shape geometries where necessary in the part.
\end{abstract}

\section{Introduction}

Hot Isostatic Pressing (HIP) is an established process for compacting powder materials far below their melting point. Processing of superalloy powders using HIP has been used for many years in different industrial applications, especially to produce high quality parts with complex geometry. In the HIP process, a steel container is filled with superalloy powder, evacuated and then submitted to simultaneous application of high pressure (about $100 \mathrm{MPa}$ ) and a temperature of about $1100{ }^{\circ} \mathrm{C}$ for several hours. During the process, volume is reduced by about $30 \%$ and porosity is completely eliminated. It is important to obtain netshape HIP parts in order to reduce machining and material costs, particularly for superalloys, or even to produce non-machineable geometries. However, the final geometry of the product can not be simply deduced from the initial one, due to non isotropic deformation, because of container stiffness and temperature gradients during consolidation process. To produce net-shape parts, it is essential to be able to forecast the behaviour of the superalloy powder and steel container during HIP process in order to predict the final geometry of the product. Numerical simulation can provide much information about the final as well as intermediate stages of the HIP process.

\section{$\underline{\text { PRECAD }}^{\mathbb{Q}}$ a Computer Assisted Design and Modelling Tool for Powder Precision Moulding}

A special tool has been developed by CEA/CEREM for the design and modelling of containers used to produce net-shape parts using Hot Isostatic Pressing (HIP). This tool is constituted of three modules : PrECAD(B/D for the design of the parts and meshing, PRECAD $B / M$ for the modelling of consolidation of the powder, and $\mathrm{PRECAD} \otimes / \mathrm{B}$ for the data base materials including powders and container. A general description of this tool is given figure 1.

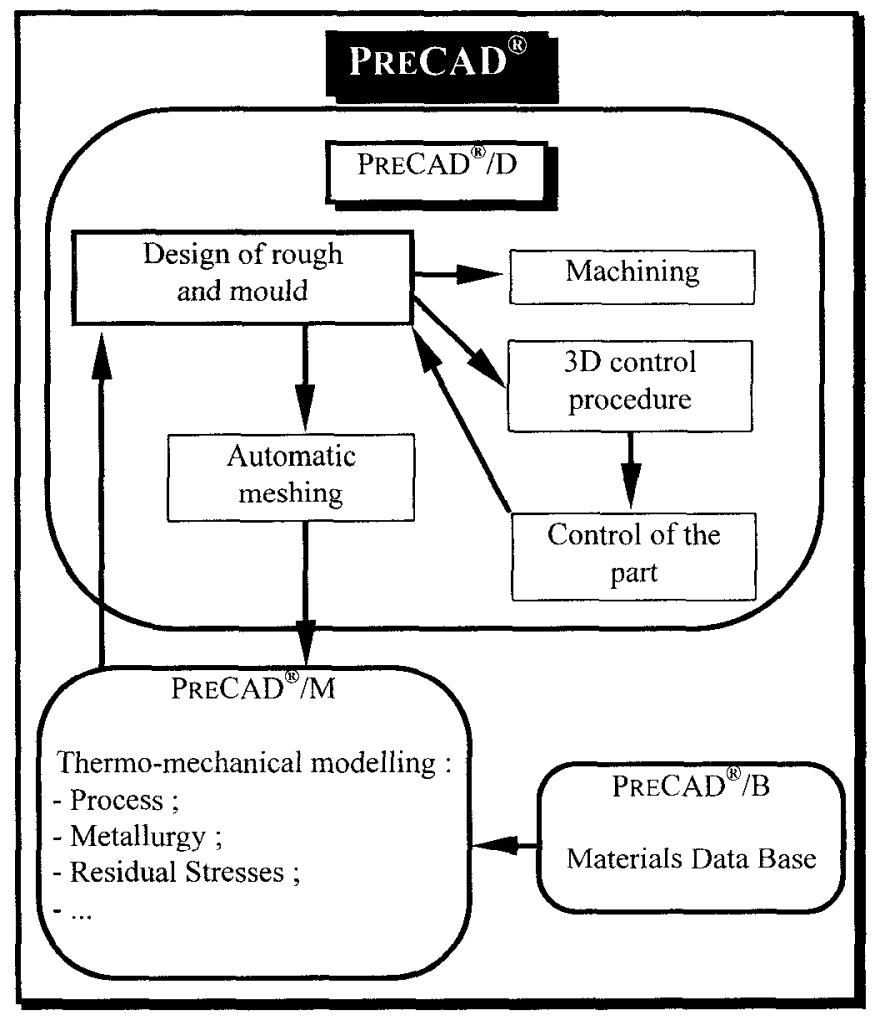

Figure 1 : General description of PRECAD ${ }^{(1)}$ tool and its modules. 


\section{Computer assisted design module PRECADEDD}

PRECADE/D is the Computer Assisted Design (CAD) module. It is used to design both the part to be realized and the container and cores necessary to produce this part "net-shape" from powder. The geometry of the design part can be provided directly by the enduser, in the form of a data file, using common CAD interfaces, such as IGES. An example of CAD image is shown figure 2.

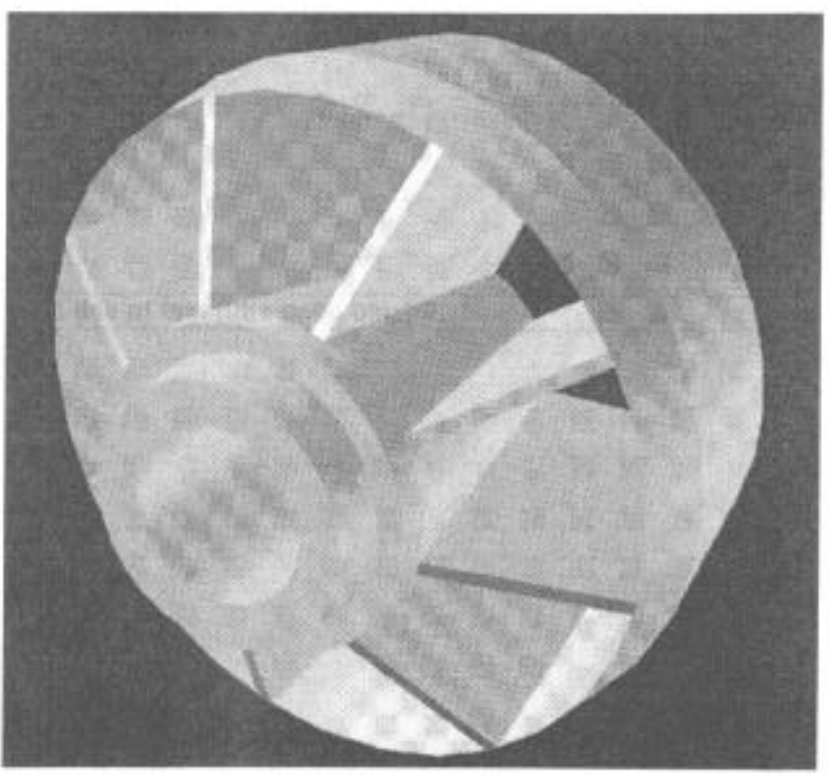

Figure 2 : $\mathrm{CAD}$ of the part to be realized.

To produce this part by net-shape HIPping, a container and some solid cores must be used. These different components constitute the mould that is shown in figure 3 . Machining programmes can be generated in the CAD module, as well as 3D control programme.

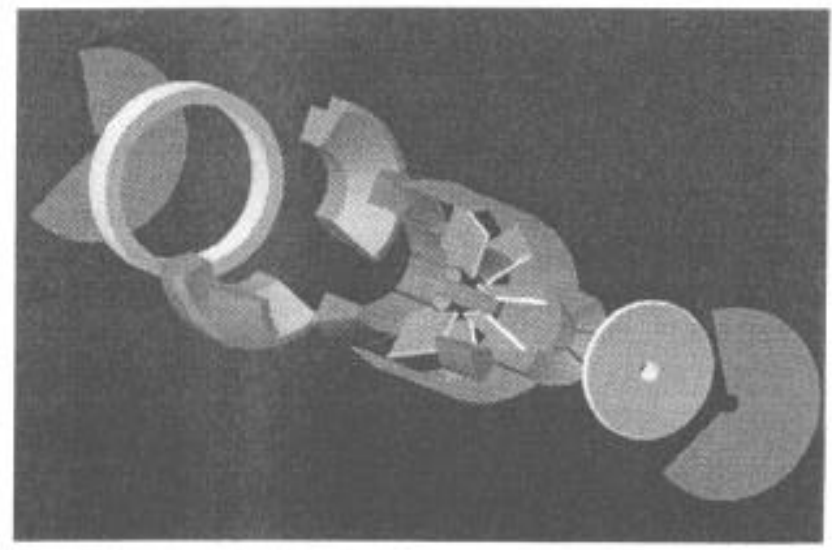

Figure 3 : Mould splinter.

Each part of the mould, powder and container are automatically meshed in this CAD module. A 3D mesh of the initial powder is shown in figure 4 .

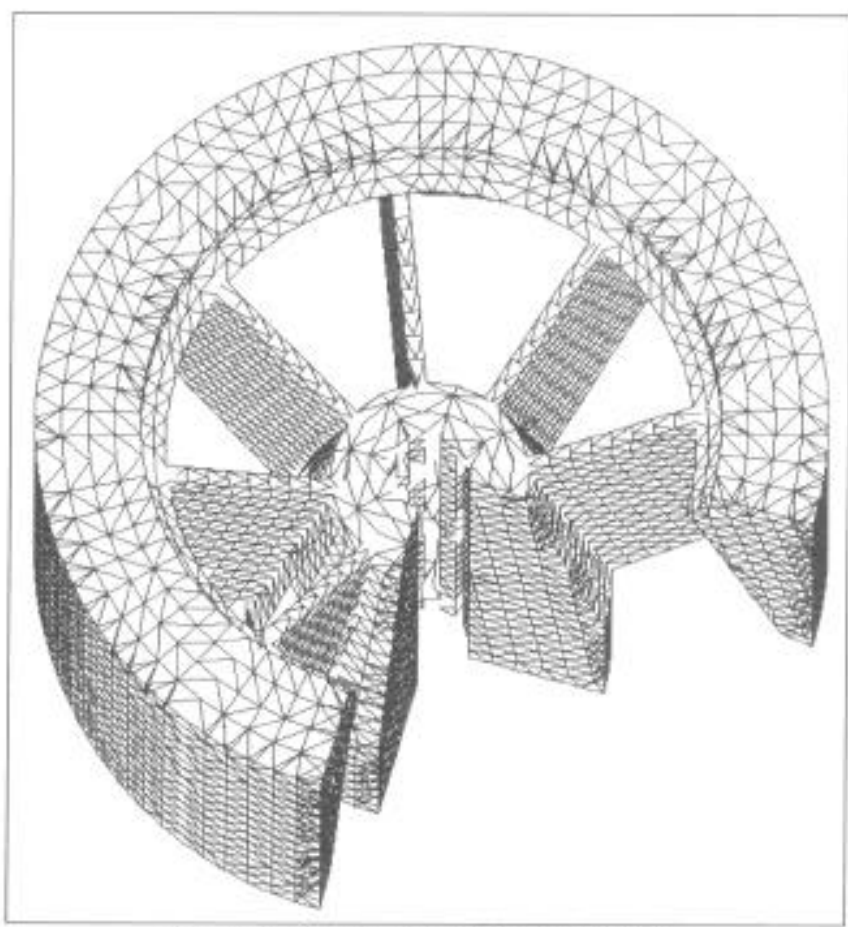

Figure $4: 3 \mathrm{D}$ mesh of the initial powder.

Meshes, materials characteristics and limit conditions are then sent to the modelling module PreCADK/M

\section{Modelling module PRECADNM}

To simulate consolidation of powder, a macromechanical approach is used. Powder is considered as a continuous medium with relative density as an internal variable. The relative density is defined as the ratio of the apparent density to the density of the fully dense material. The behaviour of the powder during consolidation is modelled by constitutive equations based on continuous media mechanics for viscoplatic metals. The flow formulation for compressible viscoplastic materials proposed by Abouaf [1] is used. This model extends, for hot deformation, the approach of Green [2] for cold deformation.

\section{Description of the model}

Constitutive equations for porous materials are developed in the framework of continuous mechanic. It is an extension of the classical $J_{2}$ Mises theory allowing volume change during viscoplastic flow. The equivalent stress $\sigma_{\text {eq }}$, which includes the effect of pressure, is defined as :

$\sigma_{e q}=\sqrt{S_{1}^{2}+\frac{3}{2} c \dot{S}_{2}^{2}}$

with

$S_{\mathrm{1}}=\operatorname{Tr}(\tilde{\sigma}) \quad$ first invariant

$\bar{S}_{2}^{2}=\operatorname{Tr}(\tilde{\sigma}, \hat{\sigma})$

second invariant

$\bar{\sigma}=\sigma-{ }_{3}^{4} S_{1} \bar{\delta}$

deviator of the stress tensor 
where $\widetilde{\sigma}$ is the Cauchy stress tensor and $\tilde{\delta}$ is the unity second order tensor. $\mathrm{c}$ and $\mathrm{f}$ are two functions representing the stress localisation induced by the porosity, and which a priori depend only on the relative density $\rho$. For full density $(\rho=1), c=1$ and $f=0$ so that the equivalent stress defined for the porous metal tends to the classical Mises equivalent stress. For small elastic strains, the strain rate $\mathrm{D}$ is partitioned into an elastic part and a viscoplastic part $D_{v}$. This last term is derived from a viscoplastic potential $\Omega$, the normality rule being assumed.

$\widetilde{D}_{v}=\frac{\partial \Omega}{\partial \widetilde{\sigma}}=\frac{\partial \Omega}{\partial \sigma_{e q}} \cdot \frac{\partial \sigma_{e q}}{\partial \widetilde{\sigma}}$

The equivalent strain rate $D^{\mathrm{eq}}$ is defined using the relation :

$\rho D_{v}^{e q} \cdot \sigma_{e q}=\tilde{\sigma}: \widetilde{D}_{v}$

Using the expression (1) of the equivalent stress, and after some calculation one get :

$D_{v}^{e q}=\frac{1}{\rho} \cdot \frac{\partial \Omega}{\partial \sigma_{e q}}$
$\widetilde{D}_{v}=\rho \cdot \frac{D_{v}^{e q}}{\sigma_{e q}} \cdot\left(f \cdot S_{1} \cdot \widetilde{\delta}+\frac{3}{2} \cdot c \cdot \widetilde{\sigma}\right)$

$\mathrm{D}_{\mathrm{v}}^{\mathrm{eq}}$ and $\sigma_{\mathrm{eq}}$ are related using the creep law of the material. A simple Norton law is chosen in which the parameters $A$ and $n$ depend only on the temperature $T$.

$D_{v}^{e q}=A(T) \sigma_{e q}^{n(T)}$

Density variations are related to $D_{v}$ through mass conservation :

$\frac{\dot{\rho}}{\rho}=-\operatorname{Tr}\left(\widetilde{D}_{v}\right)$

\section{Description of the calculation}

Finite Element Method (FEM) is used in $\mathrm{PRECAD}^{\circledR} / \mathrm{M}$ module Simulation of HIP is available for plane strain, plane stress, generalized plane strain, axisymetric and tridimensional analysis.

The modelling procedure enables the user to carry out an incremental thermo-mechanical non linear analysis. For each time step, a thermic procedure first calculates a thermal map of the mesh. This procedure enables linear and non linear computations with conduction, convection and radiation. The thermo dependant material parameters are then calculated and sent to the mechanical non linear procedure. There, the non linearity can result either from the material (visco-plasticity) or from large displacement, even from both [3].

The material non linearity are integrated using a Runge-Kutta 2.1 method. A flow chart of the elastic-viscoplastic finite element program is given figure 5 [4].

Thermal history of the material is modelled, giving the possibility to predict the mechanical properties as well as the microstructure of the consolidated powder at the end of HIP process.

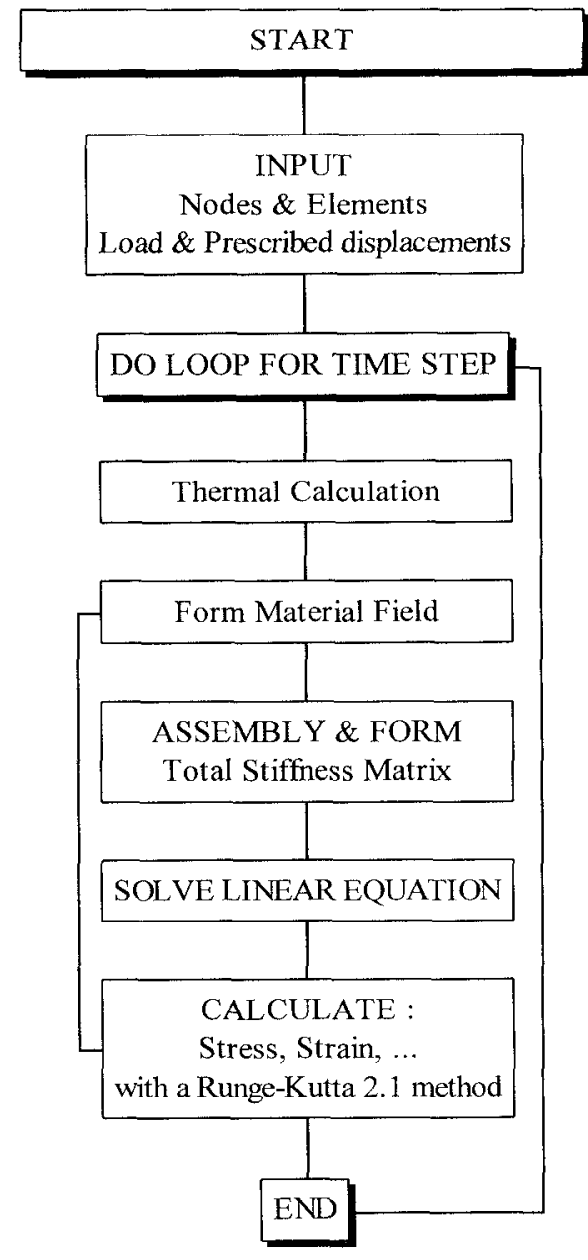

Figure 5 : Flow chart of the elastic-viscoplastic finite element program

\section{Data base module PRECAD $\underline{B}^{1 \mathrm{~B}}$}

The use of simulation requires the constitution of material data files containing physical and thermo-mechanical properties of the materials (Young modulus, Poisson's ratio, thermal expansion coefficient, creep properties, thermal conductivity, ...) including coefficients of the porous constitutive equations for powder.

The material parameters for the model of Abouaf are introduced through four functions : $A(T), n(T), c(\rho)$ and $f(\rho)$.

\section{Creep law parameters}

The functions $\mathrm{A}(\mathrm{T})$ and $\mathrm{n}(\mathrm{T})$, describing the creep law being independent of the density of the material, are identified on the dense material using uniaxial compression tests. The temperature is introduced through an activation energy.

The experiments are performed at different temperatures. For each temperature, several axial deformation rates have been applied on the same specimen using the strain rate jump method. The resultant 
stresses have been recorded. The power creep law has been fitted on the experimental curves strain rate - stabilized stress with a good accuracy.

Function $f$

The identification of the function $f(\rho)$ is obtained on interrupted HIP tests through the measure of the densification kinetic.

During the densification of cylindrical samples under the pressure $P$ and the temperature $T$, the evolution of the relative density is related to the function $f$ through the relation :

$f(\rho)=\frac{1}{9}\left(\frac{\dot{\rho} / \rho}{A . P^{n}}\right)^{\frac{2}{n+1}}$

Different HIP conditions are tested. For each HIP cycle, various step durations have been chosen and the relative density of the partially dense materials has been measured. A simple time derivation of the interpolated curves is then performed to obtain the master curves relating the densification rates with the relative densities. From these curves and knowing the creep parameters, it is possible to established the curve $f(\rho)$.

Using this experimental procedure for $316 \mathrm{LN}$ stainless steel, it has been shown that the rheological function $\mathrm{f}$ is independent of both the temperature and the pressure even on a large range of $\mathrm{T}$ and $\mathrm{P}$ (temperature from $800^{\circ} \mathrm{C}$ to $1125^{\circ} \mathrm{C}$ and pressure from 15 to $100 \mathrm{MPa}$ ) [5]. Thus the function $f$ depends only on the relative density $\rho$. This experimental result is in agreement with the theoretical assumption assumed by Abouaf concerning the independence of this function with $\mathrm{T}$ and $\mathrm{P}$.

\section{Function c}

The identification of the function $c(\rho)$ is obtained from uniaxial compression tests on porous samples.

Uniaxial compression tests under imposed strain rate have been performed on the porous samples obtained with interrupted HIP cycles. We may define now a new function called $s(\rho)$ as the ratio of the measured stress on the porous material characterized by the relative density $\rho$, over the stress of the dense material submitted to the same strain ratc. Using the equations of the model, and after some calculation one obtain the following relations :

$c(\rho)=s(\rho)_{n+1}^{-2 n}-f(\rho)$

with

$s(\rho)=\frac{\left(\sigma_{z}\right)_{\rho}}{\left(\sigma_{z}\right)_{\rho=1}}$

The experimental function $s(\rho)$ is first determined, then the rheological function $c(\rho)$ is calculated.

A general framework of the experimental determination is given figure 6 .

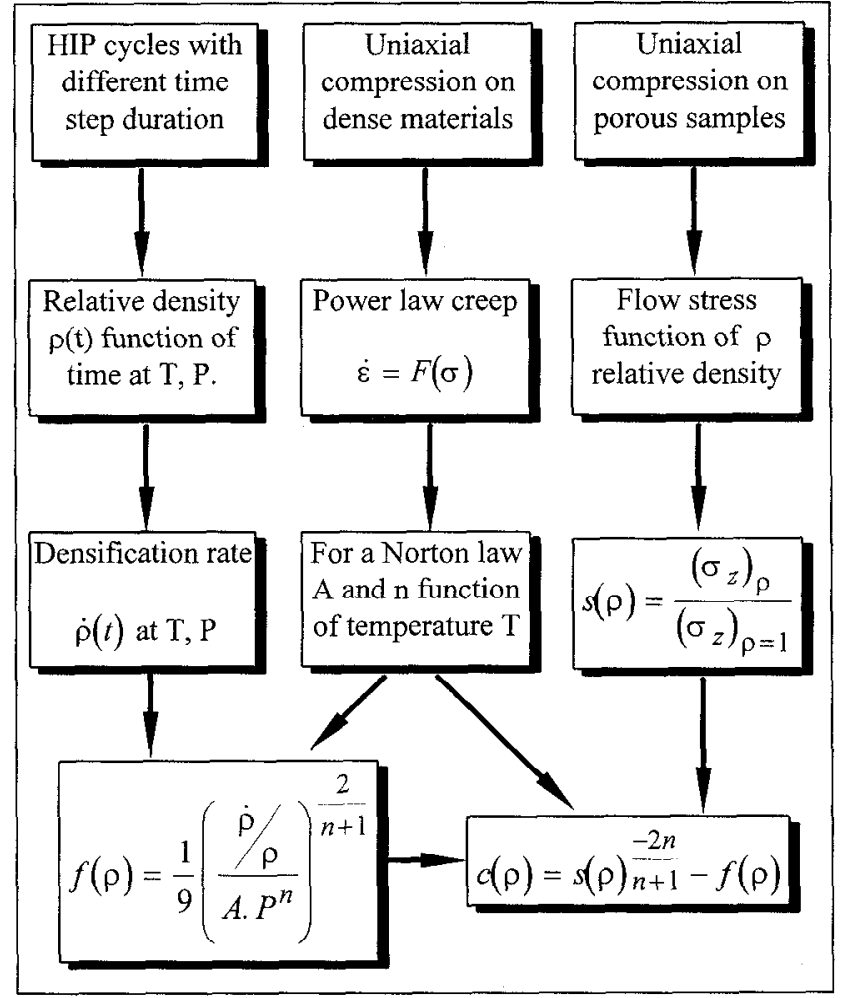

Figure $6:$ General framework of the experimental determination.

\section{Data Base for Superalloys}

A large amount of experiments have been performed on superalloys powder, to identify the parameters for modelling. The most studied are Nickel base superalloys but some results are also available for Cobalt base superalloys. Such data are directly usable in PreCAD.

\section{Nickel base superalloys}

Several Nickel base superalloys have been already studied : René 95 [6], Astrolloy [7, 8] and MERL76 [9]. These materials are usually produced by gas atomisation, however Lafer [8] has also studied a rotating electrod atomized Astrolloy made by Tecphy. The chemical composition of these materials is given in table $\mathrm{I}$.

Creep law of the material is usually of Norton type (equation 9), but a Sellars-Tegart relation is often appropriate to cover a large range of temperatures and strain rates.

$D_{v}^{e q}=A(T)\left[\operatorname{sh}\left(\alpha \sigma_{e q}\right)\right]^{n}$

Thermal dependency of the A parameter is usually take into account with an Arhenius law :

$$
A(T)=A_{0} \cdot \exp \left(\frac{-Q}{R T}\right)
$$

The creep law parameters are $A_{0}, n, \alpha$ and $Q$ that must be experimentally determined for each material. 
Table I : Chemical composition of Nickel base superalloys studied in litterature.

René 95 [6], Gas atomized powder produced by TFCPHY.

\begin{tabular}{|c|c|c|c|c|c|c|c|c|c|c|}
\cline { 2 - 10 } \multicolumn{1}{c|}{} & $\mathrm{Ni}$ & $\mathrm{Cr}$ & $\mathrm{Co}$ & $\mathrm{Mo}$ & $\mathrm{W}$ & $\mathrm{Al}$ & $\mathrm{Ti}$ & $\mathrm{Nb}$ & $\mathrm{Zr}$ & $\mathrm{B}$ \\
\hline (\% weight) & Bal. & 14.0 & 8.0 & 3.5 & 3.5 & 3.5 & 2.5 & 3.5 & 0.05 & 0.01 \\
\hline
\end{tabular}

Astrolloy [7, 8], Gas (ATGP3 and AA) and Rotating electrod (RE) atomized powder produced by TECPHY.

\begin{tabular}{|c|c|c|c|c|c|c|c|c|c|c|}
\cline { 2 - 11 } \multicolumn{1}{c|}{} & $\mathrm{C}$ & $\mathrm{Co}$ & $\mathrm{Cr}$ & $\mathrm{Mo}$ & $\mathrm{Al}$ & $\mathrm{Ti}$ & $\mathrm{B}$ & $\mathrm{Zr}$ & $\mathrm{O}_{2}$ & $\mathrm{~N}_{2}$ \\
\hline ATGP3 (\% weight) & $<0.035$ & 17 & 15 & 5 & 4 & 3.5 & 0.03 & 0.05 & - & - \\
\hline AA (\% weight) & 0.02 & 16.5 & 15 & 5 & 4 & 3.5 & 0.025 & - & $<0.01$ & $<0.005$ \\
\hline RE (\% weight) & 0.013 & 16.88 & 14.85 & 5.05 & 3.96 & 3.37 & 0.031 & - & $<0.024$ & $<0.025$ \\
\hline
\end{tabular}

Table II : Chemical analysis of the SY625 Ni-base superalloy produced by TECPHY (in \% weight).

\begin{tabular}{|c|c|c|c|c|c|c|c|c|c|c|c|c|c|c|c|c|c|c|}
\hline$\overline{\mathrm{Ni}}$ & $\mathrm{Cr}$ & Mo & $\mathrm{Nb}$ & $\mathrm{C}$ & 0 & $N$ & $\mathrm{Si}$ & $\mathrm{Mn}$ & $S$ & $\mathrm{P}$ & $\mathrm{Ti}$ & $\mathrm{Al}$ & $\mathrm{Zr}$ & $\mathrm{Fe}$ & $\mathrm{Cu}$ & W & V & Co \\
\hline Bal. & 20.39 & 8.61 & 3.41 & 0.013 & 0.041 & 0.03 & 0.183 & 0.015 & 0.0012 & 0.007 & 0.01 & $<0.005$ & 0.0065 & 0.204 & $<0.005$ & 0.092 & 0.044 & 0.014 \\
\hline
\end{tabular}

The experimental results are creep parameters of the materials at HIPping temperature (summarized table III) and rheological functions $f$ and $c$ of Abouaf's model (figure 7 and 8 ). These functions have been identified for relative density from $80 \%$ to $100 \%$. The tapped density of the powder is nearly $64 \%$, so functions have to be extrapolated for density ranging from $64 \%$ to $80 \%$. Figure 7 and 8 show that there is a great discrepancy between results of Abouaf [7] and Lafer [8] on an argon atomized Astrolloy powder. Processing of powder (gas atomization or rotating electrod) is extremly important as shown by the exponents of power law creep (2.52 for AA and 4.41 for RE).

Table III : Creep parameters of some Nickel base Superalloys.

\begin{tabular}{|c|c|c|c|c|}
\hline Ref. & $\mathrm{A}$ & $\mathrm{n}$ & $\alpha$ & $\mathrm{Q} / \mathrm{R}$ \\
\hline $\mathrm{ATGP} 3[7]$ & $3.42 .10^{18}$ & 2.136 & $0.864 .10^{-2}$ & 67652 \\
\hline René95 [6] $\left(950^{\circ} \mathrm{C}\right)$ & $1.27 .10^{-12}$ & 3.34 & - & - \\
\hline $\mathrm{AA}[8]\left(1000^{\circ} \mathrm{C}\right)$ & $4.3 .10^{-9}$ & 2.52 & - & - \\
\hline $\mathrm{RE}[8]\left(1000^{\circ} \mathrm{C}\right)$ & $3.26 .10^{-14}$ & 4.41 & - & - \\
\hline
\end{tabular}

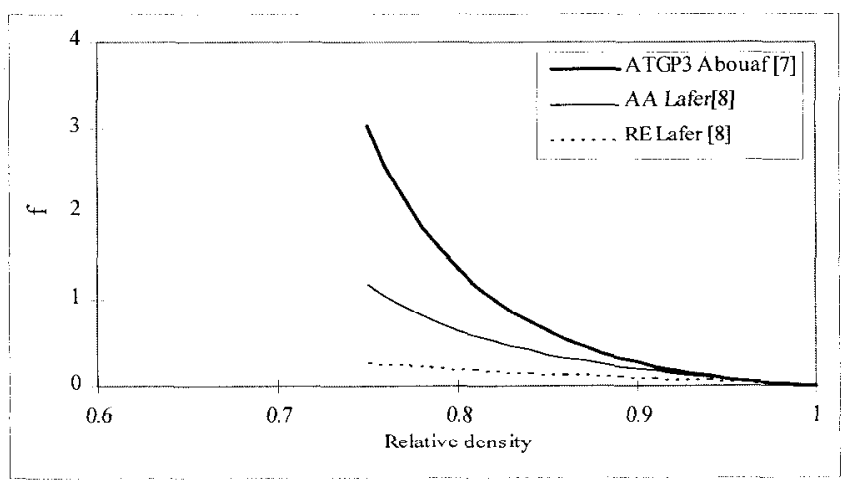

Figure 7 : "f" function for some Nickel base superalloys.

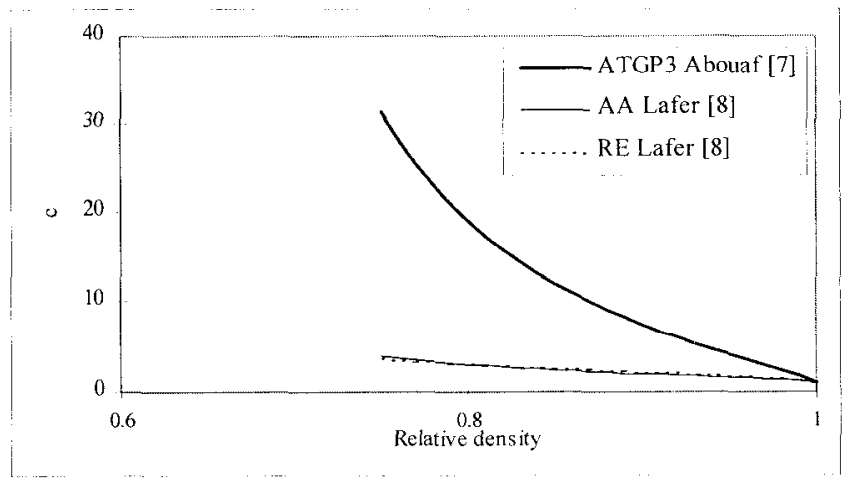

Figure $8:$ "c" function for some Nickel base superalloys.

Experiments on Superalloy SY 625 made by powder metallurgy

The alloy used in this study is the SY625, a solid solutionstrenghtened Nickel base superalloy made by TECPHY, France. It combines strength, good corrosion resistance at elevated temperature (up to $540^{\circ} \mathrm{C}$ ) and good weldability. It has thus found applications in marine environments, aerospace, oil and gas industry and nuclear environments.

Moreover the powder of alloy SY 625 take advantage of all the benefits of powder such as near net-shape forming and fine microstructure. All these properties of the SY625 PM are due to its composition (see table II) [10].

The Nickel is the major constituent. A chemical composition of 50 to $55 \%$ (weight percent) allows the alloy to have a maximum yield strenght. The addition of chromium increases the corrosion resistance and with molybdenum and niobium, they enhance the solid solution strenghtening because of their high atomic volume. 
The titanium content is kept as low as possible because it induces titanium carbides and nitrides precipitations at prior particle boundaries [11]. The nitrogen content is dependent upon atomization event and so it is more difficult to precisely control. The SY 625 PM is made without iron because it does not promote either the strenght or the corrosion resistance.

TECPHY made experiments on SY 625 PM at different temperatures of HIPping. Optimized temperature is determinated in order to have a maximum yield stress. The HIPping conditions are then 2 hours at $1120^{\circ} \mathrm{C}$ and $100 \mathrm{MPa}$. The reference HIP cycle is shown figure 7 .

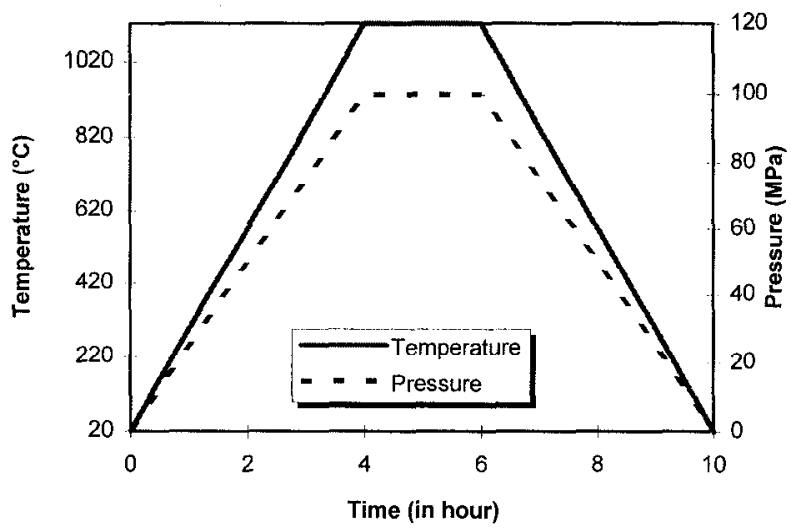

Figure 7 : Optimized HIP cycle for consolidation of SY 625 PM.

Uniaxial compression tests have been performed by TECPHY on SY625 dense material at different temperatures [12]. Creep parameters for a Norton law can be identified at $1100^{\circ} \mathrm{C}$ as shown in figure 8. The creep parameters are $n=3.49$ and $\log (A)=-21.70$.

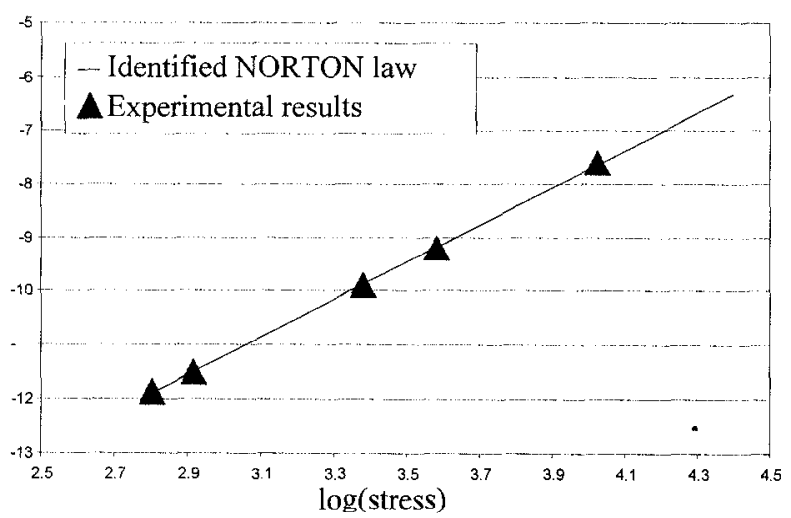

Figure 8 : Uniaxial compression tests at $1100^{\circ} \mathrm{C}$ on dense SY625.

Other experiments are on going at CEA/CEREM to identify the rheological functions $f$ and $c$ of Abouaf's model, using the experimental procedure presented earlier. Porous samples have been realized for relative density of $70 \%$ to $100 \%$, to be abble to interpolate the $f$ and $c$ functions on all the range of density.

\section{Validation Process of Modelling}

The modelling module $\mathrm{PRCCAD}^{\circledR} / \mathrm{M}$ has becn validated on real 3D-part for titanium alloys [13], by comparison between the modelled and the realized part (Figure 9). Dimensions have been measured on a 3D-control machine with an accuracy of $4 \mu \mathrm{m}$. Initial geometry is measured, then modelled and the part is realized in parallel. Final geometry of the part is measured after decanning on internal and external geometries. Comparison of the two geometries, modelled and realized, is made with the CAD module. The accuracy of the modelling is $\pm 50 \mu \mathrm{m}$ for internal cavities (Figure 10 and table IV) [14]. So net-shape complex internal geometries can be realized without extra machining after HIP cycle. External geometries are finally machined using conventional machining. The same validation process is on going for nickel base superalloy SY625.

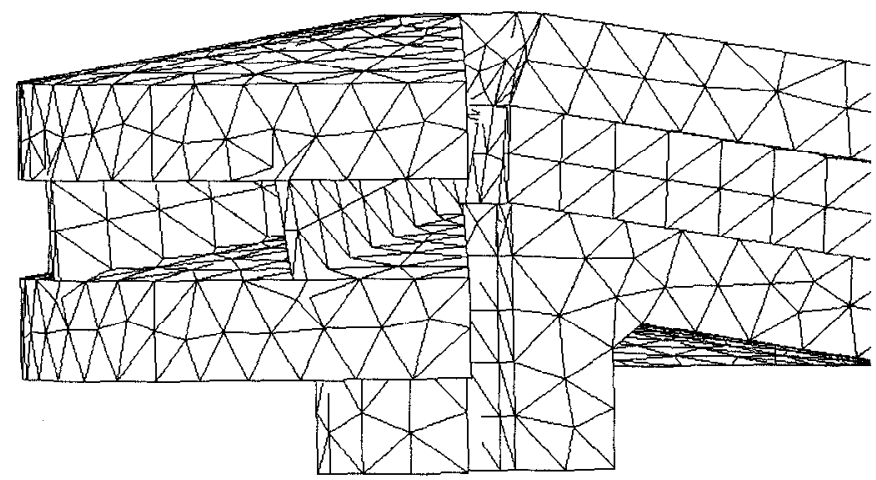

Figure 9:3D-mesh of powder for the validation part. External view (left) and representative section (right)

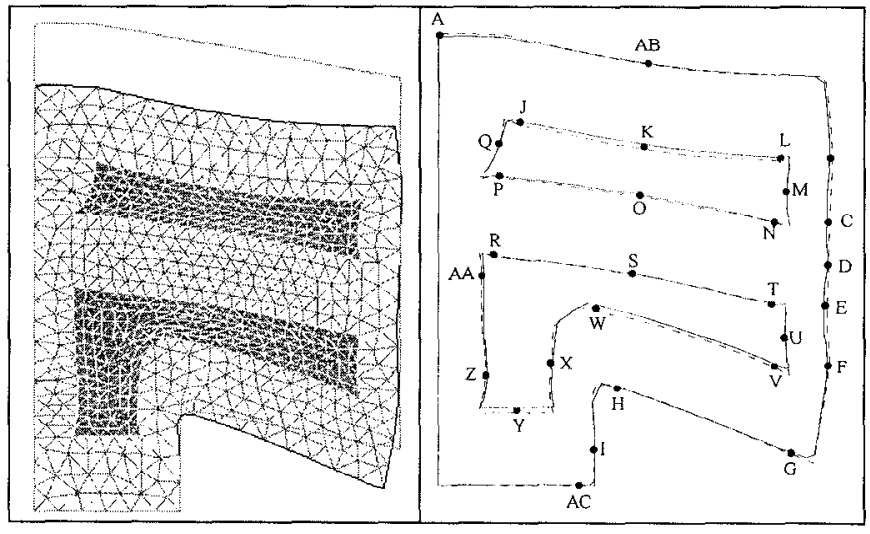

Figure 10 : Deformed mesh (left). Comparison between modelling and realized part on the representative section (right).

Table IV : Comparison of realized and modelled internal geometries (in mm)

\begin{tabular}{|c|c|c|c|c|c|c|}
\cline { 2 - 6 } \multicolumn{1}{c|}{} & $\mathrm{N}$ & $\mathrm{O}$ & $\mathrm{P}$ & $\mathrm{R}$ & $\mathrm{S}$ & $\mathrm{T}$ \\
\hline DX & 0.00 & 0.00 & 0.00 & 0.00 & 0.00 & 0.00 \\
\hline DY & -0.09 & 0.14 & -0.10 & -0.19 & 0.08 & -0.27 \\
\hline
\end{tabular}




\section{Conclusion}

A computer assisted design and modelling tool for superalloy precision moulding, PreCAD®, has been presented. It allows design, meshing and modelling for the HIPping of 2D and 3D parts. Thermo-mechanical modelling is performed with the GreenAbouaf's viscoplastic model, using finite element method. Final geometry, temperature distribution and relative density map are available. Validation of the modelling by the comparison with an actually manufactured $3 \mathrm{D}$ parts indicates $\mathrm{a} \pm 50 \mu \mathrm{m}$ accuracy on internal geometries of a titanium alloy parts. Such areas of the part can thus be realized net-shape. Only the external geometry has to be machined after decanning. This tool is industrially used to optimize geometries of cores and containers to realize net-shape parts by HIPping of titanium and stainless stecl powders. Data base is also available now for SY625 Nickel base superalloys, and validation process is on going.

\section{Acknowledgement}

This study has been supported by TURBOMECA. It has been done in the scope of IsOPREC ${ }^{\circledR}$ agreement between TURBOMECA, SEP, TECPHY and CEA/CEREM.

\section{$\underline{\text { References }}$}

[1] Abouaf M., Chenot J.L., "Simulation numérique de la déformation à chaud de poudres métalliques", Journal de Mécanique Théorique Appliquée, Vol.5, p.121, 1986.

[2] Green R.J., "A Plastic Theory for Porous Solid", International Journal of Mechanical Science, Vol.14, pp.215-224, 1972.

[3] De Gayffier A., "Algorithme non-linéaire de CASTEM2000 (NONLIN et INCREM)", Rapport CEA, $\mathrm{n}^{\circ}$ DMT/94-188, 1994

[4] Imatani I., "Studies on nelastic Constitutive Relationship for High Temperature Materials and its Application to Finite Element Analysis", Kyoto University, March 1990.
[5] Dellis C., Abondance D., Bouaziz O., Stutz P., "Rhéologie des Poudres Métalliques à Chaud", Acte du colloque SF2M sur les traitements des poudres et leurs conséquences, Paris, 18-20 mars 1996.

[6] Bouvard D., "Rhéologie des poudres métalliques au cours de la mise en forme à haute température", Thèse de Docteur ès-sciences, UJF - INPG, septembre 1989.

[7] Abouaf M., "Modélisation de kla compaction de poudres métalliques frittées", Thèse de Docteur ès-sciences, UJFINPG, mai 1985.

[8] LAFER M., "Comportement de poudres métalliques et de composites particulaires lors de la compaction isostatique à chaud", Thèse de l'Université Joseph Fourier - Grenoble I, Spécialité Mécanique, avril 1992.

[9] Noharah A., Soh T., Nakagawa T, "Numerical simulation of hot isostatic pressing", Proceedings of the $3^{\text {rd }}$ International Conference on Hot Isostatic Pressing, London, MPR Publishing Services, 1986.

[10] Davidson J.H., "The Influence of Processing Variables on the Microstructure and Properties of PM 625 Alloy", Proceedings of the International Symposium on Superalloys 718 and 625, Pittsburgh, 24-26 june 1991.

[11] Ferrer L., "Précipitation, recristallisation et déformation à chaud de l'alliage 625. Application aux traitements thermomécaniques", Thèse de I'Institut National Polytechnique de Toulouse, 1992.

[12] Pierronnet M., Raisson G., Private communication, TECPHY, september 1995.

[13] Abondance D., "Modélisation thermomécanique d'un procédé de mise en forme aux cotes de pièces complexes par compression isostatique à chaud de poudre de TA6V", Thèse de l'Université Joseph Fourier - Grenoble I, Spécialité mécanique, 06 février 1996.

[14] Abondance D., Dellis C., Baccino R., Bernier F., Moret F., De Monicault J.M., Guichard D., Stutz P, and Bouvard D., "Numerical Modelling of Near-Net-Shape Hipping of TA6V powder", Proceedings of Titanium 1995, Birmingham, October 1995. 